\title{
Glucosidase inhibitory activity and antioxidant activity of flavonoid compound and triterpenoid compound from Agrimonia Pilosa Ledeb
}

\author{
Xi Liu', Liancai Zhu*, Jun Tan², Xuemei Zhou', Ling Xiao ${ }^{1}$, Xian Yang ${ }^{3}$ and Bochu Wang ${ }^{\text {** }}$
}

\begin{abstract}
Background: In Chinese traditional medicine, Agrimonia pilosa Ledeb (APL) exhibits great effect on treatment of type 2 diabetes mellitus (T2DM), however its mechanism is still unknown. Considering that T2DM are correlated with postprandial hyperglycemia and oxidative stress, we investigated the a-glucosidase inhibitory activity and the antioxidant activity of flavonoid compound (FC) and triterpenoid compound (TC) from APL.

Methods: Entire plants of APL were extracted using 95\% ethanol and 50\% ethanol successively. The resulting extracts were partitioned and isolated by applying liquid chromatography using silica gel column and Sephadex LH 20 column to give FC and TC. The content of total flavonoids in FC and the content of total triterpenoids in TC were determined by using UV spectrophotometry. HPLC analysis was used to identify and quantify the monomeric compound in FC and TC. The a-glucosidase inhibitory activities were determined using the chromogenic method with p-nitrophenyl-a-D-glucopyranoside as substrate. Antioxidant activities were assessed through three kinds of radical scavenging assays (DPPH radical, ABTS radical and hydroxyl radical) \& $\beta$-carotene-linoleic acid assay.
\end{abstract}

Results: The results indicate $\mathrm{FC}$ is abundant of quercitrin, and hyperoside, and TC is abundant of $1 \beta, 2 \beta, 3 \beta$, 19a-tetrahydroxy-12-en-28-oic acid (265.2 mg/g) and corosolic acid (100.9 mg/g). The FC \& the TC have strong a-glucosidase inhibitory activities with $\mathrm{IC}_{50}$ of $8.72 \mu \mathrm{g} / \mathrm{mL}$ and $3.67 \mu \mathrm{g} / \mathrm{mL}$, respectively. We find that $\mathrm{FC}$ show competitive inhibition against a-glucosidase, while the TC exhibits noncompetitive inhibition. Furthermore, The FC exhibits significant radical scavenging activity with the $\mathrm{EC}_{50}$ values of $7.73 \mu \mathrm{g} / \mathrm{mL}, 3.64 \mu \mathrm{g} / \mathrm{mL}$ and $5.90 \mu \mathrm{g} / \mathrm{mL}$ on DPPH radical, hydroxyl radical and ABTS radical, respectively. The FC also shows moderate anti-lipid peroxidation activity with the $\mathrm{IC}_{50}$ values of $41.77 \mu \mathrm{g} / \mathrm{mL}$ on inhibiting $\beta$-carotene bleaching.

Conclusion: These results imply that the FC and the TC could be responsible for the good clinical effects of APL on T2MD through targeting oxidative stress and postprandial hyperglycaemia. So APL may be good sources of natural antioxidants and a-glucosidase inhibitors exhibiting remarkable potential value for the therapy of T2DM.

Keywords: Type 2 diabetes mellitus, Flavonoid compound, Triterpenoid compound, Postprandial hyperglycemia, Oxidative stress

\footnotetext{
* Correspondence: zhuliancai75@126.com; wangbc2000@126.com

'Key Laboratory of Biorheological Science and Technology (Chongqing University), Ministry of Education, College of Bioengineering, Chongqing University, No. 174, Shapingba Main Street, Chongqing 400030, China Full list of author information is available at the end of the article
} 


\section{Background}

Type II diabetes mellitus (T2DM) as an epidemic disease, associated with increased significant social and financial burden, is a cause of very high morbidity and mortality in the world [1]. It is well-known that the genesis and progression of T2DM is generally attributed to several factors including persistent hyperglycemia toxicity, oxidative damage and lipotoxicity, etc. [1]. A widely held notion is that postprandial hyperglycemia (PPHG) is a primary risk factor in the development of T2DM and its complications via multi-factorial mechanisms [2]. Meanwhile, increasing evidences suggest that oxidative stress (OS) is involved in the pathogenesis of T2DM and the development of diabetic complications through the mechanism of impairing oxidation reduction system, leading to $\beta$-cell failure and insulin resistance $[3,4]$.

Despite great efforts that have been made to normalize blood glucose level in clinic practice, it is still a formidable challenge. Even more difficult is the control of PPHG [5]. Nowadays, the more attentions are paid to control PPHG based on the $\alpha$-glucosidase, $\alpha$-amylase, amylin analogues as targets [6]. Among them, most therapeutic approaches for controlling PPHG are the pharmacological inhibitors with greatest effect on $\alpha$-glucosidase including acorbose, miglilol, emigitate, voglibiose, etc. [6,7]. However, the continuous use of those synthetic agents should be limited because those agents may cause side effects such as flatulence, abdominal cramp, vomiting, and diarrhea $[8,9]$. Numerous studies have been carried out to screen natural agents (active natural components and crude extracts) to inhibit $\alpha$-glucosidase activity without or with fewer side effects [10]. On the other hand, overwhelming researches suggest that natural antioxidants may be used to reduce oxidative damage and decrease the occurrence of diabetic complications $[11,12]$. Therefore, it is a prospective strategy that PPHG and ROS are used as dual-target to screen the natural drugs to combat the multiple disorders of T2DM.

Agrimonia pilosa Ledeb (APL), a Chinese traditional medicinal plant of Rosaceae family, is widely used to treat blood, tumor, gastrointestinal, gynecological, genitourinary diseases in Chinese traditional medicine [13]. Especially, in the past several decades Chinese traditional medicine have shown the great effect of APL on T2DM in clinical practice. But it is unclear how APL acts on T2DM. Chemical composition studies reveal that the APL is abounded with polyphenols, terpenoids and coumarins etc. [14,15]. It has been reported that some flavonoids and terpenoids from medicinal plants have the inhibitory activities of $\alpha$-glucosidase [16]. Moreover, the abundant flavonoids are mainly responsible for the antioxidant activities of many herbs [17]. Therefore, we speculated that the APL could combat T2DM through targeting PPHG and OS.
In this study, we isolated the flavonoid compound (FC) and the triterpenoid compound (TC) from APL, and evaluated their $\alpha$-glucosidase inhibition activity and antioxidative activities. Meanwhile, the inhibitory effect on $\alpha$-glucosidase of the compounds with the different ratio of the FC and the TC also was tested. Furthermore, the inhibition kinetics against $\alpha$-glucosidase of the FC and the TC were studied.

\section{Methods \\ Chemicals}

Butylated hydroxyl toluene (BHT), gallic acid, $\beta$-carotene, linoleic acid, 1,1-diphenyl-2-picrylhydrazyl (DPPH“), $\rho$-nitrophenyl $\alpha$-D-glucopyranoside(PNPG), 3,5-dinitro salicylic acid, soluble potato starch and 1-deoxyrojirimycine, $\alpha$ Glucosidase (from Saccharomyces cerevisiae), HPLC grade methanol and acetonitrile were purchased from Sigma Chemical Co. (St. Louis, MO, USA). Folin-Ciocalteu reagent was obtained from E. Merck Co. (Darmstadt, Germany). Standards including oleanolic acid, ursolic acid, vitexin, rutin, hyperoside, luteolin-7-O- $\beta$-D-glucopyranoside, quercitrin, quercetin, luteolin, apigenin and kaempferol were obtained from the National Institutes for Food and Drug Control (Beijing, China). 1 $\beta, 2 \beta, 3 \beta, 19 \alpha$-tetrahydroxy-12-en-28-oic acid, tormentic acid, maslinatic acid, corosolic acid and tiliroside are isolated and identified by ourselves in lab. All other reagents were analytical grade procured from indigenous manufacturers.

\section{Plant materials and preparation of the extract}

The dried entire plants of APL were purchased from Western Medicine City (Chongqing, China) in 2011 and verified by Changhua Wang (Chongqing Academy of Chinese Materia Medica, China). Extracts were obtained as follows: In brief, the dried entire plants $(2 \mathrm{~kg})$ were chopped into small pieces (40 mesh) and soaked overnight in $40 \mathrm{~L}$ of $95 \%$ ethanol, then was under refluxing at $100^{\circ} \mathrm{C}$ for three times for $90 \mathrm{~min}, 90 \mathrm{~min}, 60 \mathrm{~min}$, respectively. The suspension was filtered to give solution A. Then the residue was extracted by $40 \mathrm{~L}$ of $50 \%$ ethanol under refluxing as above condition to give solution B. The two filtrate solvents were evaporated in a rotary vacuum evaporator at $45^{\circ} \mathrm{C}$ and then lyophilized to give extract $\mathrm{A}$ and extract $\mathrm{B}$. Then the extracts were separated using liquid column chromatography (see Figure 1). Finally, according to thin layer chromatography control with $10 \%$ sulfate in ethanol as color-developing agent, Fr.A Ib2, Fr.A IIc and Fr.A IIb3 were mixed to give triterpenoids compound (TC) and Fr.A Ic, Fr.A Ib4, Fr.B IId, Fr.B IIe, Fr.B IIf, Fr.B IIg, and Fr.B IIh were mixed to give flavonoid compound (FC). The TC powder $(2.5646 \mathrm{~g})$ and the $\mathrm{FC}$ powder $(9.5375 \mathrm{~g})$ were stored at $0-4^{\circ} \mathrm{C}$. 


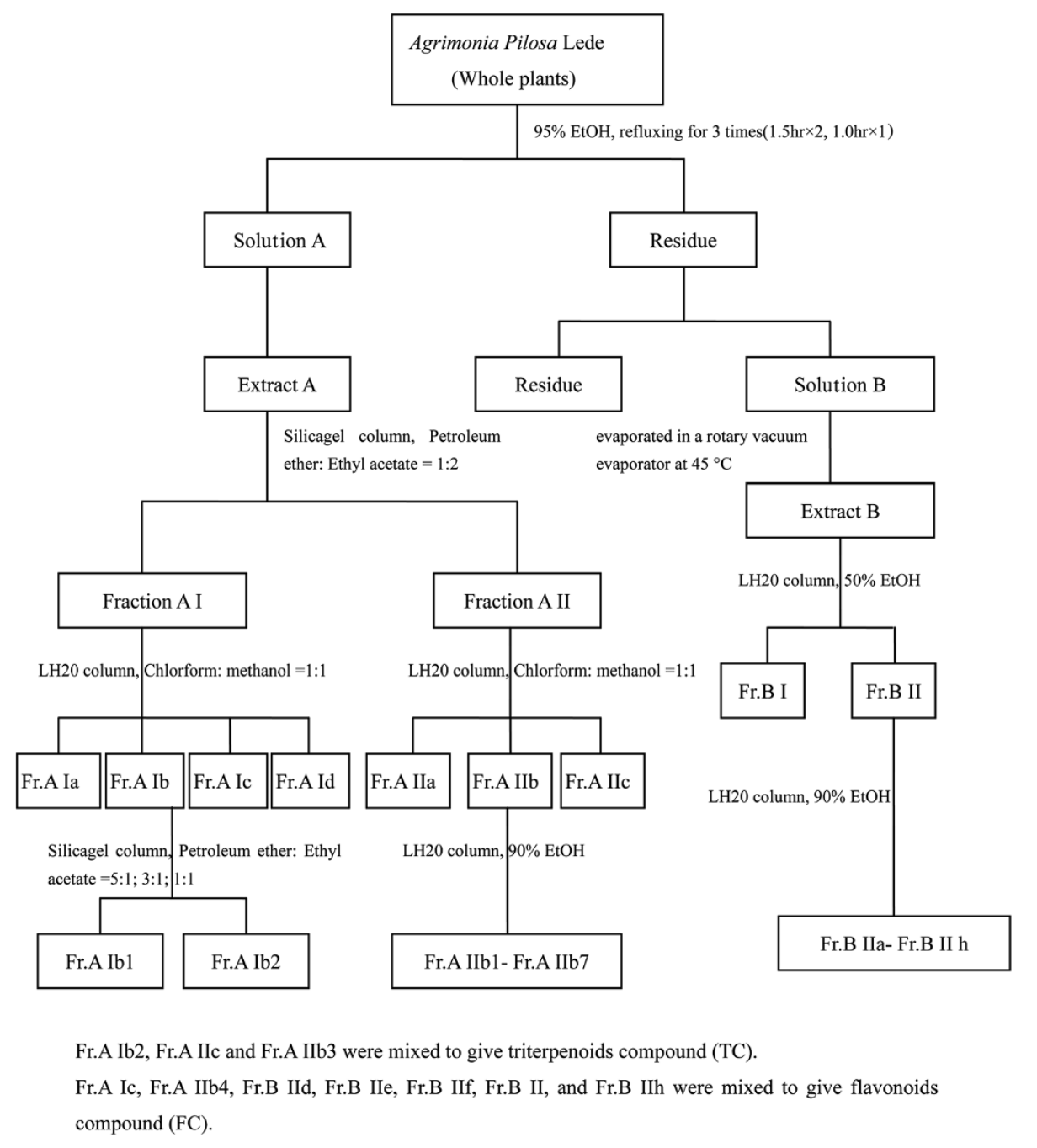

Figure 1 The collected procedure of flavonoid compound (FC) and triterpenoid compounds (TC).

\section{Determination of total flavonoids content}

Total flavonoids content in FC was determined by using the aluminium chloride colorimetric method. A mixture of $0.5 \mathrm{~mL}$ sample, $100 \mu \mathrm{L} 10 \%$ aluminum chloride, $100 \mu \mathrm{L}$ $1 \mathrm{M}$ potassium acetate and $2.3 \mathrm{~mL}$ distilled water were incubated at room temperature for $30 \mathrm{~min}$. The absorbance was measured at $415 \mathrm{~nm}$. Quercetrin as a standard was used to make the calibration curve. The estimation of total flavonoids in the extracts was carried out in triplicate and the results were averaged.

\section{Determination of total triterpenoids content}

Total triterpenoid content in TC was determined by using UV spectrophotometry [18], with some modifications. Reference substance $(0.8 \mathrm{~mL})$ was moved in $10 \mathrm{~mL}$ volumetric flask, to evaporate ethanol in water bath at $85^{\circ} \mathrm{C}$ and then add $0.4 \mathrm{~mL} 5 \%$ vanillin-glacial acetic acid and $1.0 \mathrm{~mL}$ perchloric acid, respectively. The mixture was kept in water bath at $80^{\circ} \mathrm{C}$ for $20 \mathrm{~min}$, cooled to room temperature in ice bath, and $5.0 \mathrm{~mL}$ glacial acetic acid was added. The solutions were mixed by manual shaking for $15-20 \mathrm{~s}$ and allowed to stand for $15 \mathrm{~min}$ at room temperature. Finally, the absorbance was measured at $765 \mathrm{~nm}$. Ursolic as a standard was used to make the calibration curve. The estimation of total triterpenoid content in the extracts was carried out in triplicate and the results were averaged.

\section{HPLC analysis of flavonoids in FC}

HPLC analysis was performed using Agilent1260 with UV detector, and chromatographic separations were conducted on a Welch ultimate XB-C18 column $(4.6 \times$ $250 \mathrm{~mm}, 5 \mu \mathrm{m})$. The solvent system was a gradient of mobile phase: soln. A: $0.1 \%$ phosphate in $\mathrm{H}_{2} \mathrm{O}$; soln. B, acetonitrile. The following gradient was used: $0-30 \mathrm{~min}$, $87 \% \mathrm{~A} ; 30-50 \mathrm{~min}, 87 \%$ A to $80 \% \mathrm{~A} ; 50-70 \mathrm{~min}, 80 \% \mathrm{~A}$ to $60 \% \mathrm{~A} ; 70-80 \mathrm{~min}, 60 \% \mathrm{~A}$ to $87 \% \mathrm{~A} ; 80-90 \mathrm{~min}$, 
87\% A. Operating conditions were as follows: flow rate, $1.0 \mathrm{~mL} / \mathrm{min}$; column temp., $30^{\circ} \mathrm{C}$; injection volume, $20 \mu \mathrm{L}$; UV detection at $350 \mathrm{~nm}$.

\section{HPLC analysis of triterpenoids in TC}

HPLC analysis was performed using Agilent 1260 with UV detector, and chromatographic separations were conducted on a Welch ultimate XB-C18 column $(4.6 \times 250 \mathrm{~mm}$, $5 \mu \mathrm{m})$. The solvent system was a gradient of mobile phase: soln. A: $0.1 \%$ formic acid in $\mathrm{H}_{2} \mathrm{O}$; soln. B: acetonitrile and methnol $(2: 1, \mathrm{v} / \mathrm{v})$. The following gradient was used: 0-10 min, 25\% A; $10-15 \mathrm{~min}, 25 \%$ A to $30 \%$ A; $15-30 \mathrm{~min}$, $30 \% \mathrm{~A}$. Operating conditions were as follows: flowrate, $1.0 \mathrm{~mL} / \mathrm{min}$; column temp., $30^{\circ} \mathrm{C}$; injection volume, $20 \mu \mathrm{L}$; UV detection at $210 \mathrm{~nm}$.

\section{Inhibition assay for a-glucosidase activity}

The $\alpha$-glucosidase inhibitory activities of $\mathrm{TC}$ and the FC were determined according to the chromogenic method with slight modifications [19]. The substrate solution p-nitrophenyl- $\alpha$-D-glucopyranoside (pNPG, Sigma Chemical Company) was prepared with $0.2 \mathrm{M}$ of Na-phosphate buffer $(\mathrm{pH}$ 6.8). The reaction mixture contained $10 \mu \mathrm{L}$ of $0.02 \mathrm{U} / \mu \mathrm{L} \alpha$-glucosidase solution in $0.2 \mathrm{M} \mathrm{Na}$-phosphate buffer (pH6.8), $10 \mu \mathrm{L}$ of a sample in DMSO (or DMSO itself as blank control) with the concentration of 20.0, 50.0, 100.0, 200.0, 400.0, $500.0 \mu \mathrm{g} / \mathrm{mL}$, respectively, $50 \mu \mathrm{L}$ of $\mathrm{Na}$-phosphate buffer (pH6.8), which were mixed and incubated at $37^{\circ} \mathrm{C}$ for $20 \mathrm{~min}$. Then, $50 \mu \mathrm{L}$ of $0.02 \mathrm{M}$ PNPG was added, and the mixture was incubated at $37^{\circ} \mathrm{C}$ for another $30 \mathrm{~min}$. Finally, the reaction was stopped by the addition of $100 \mu \mathrm{L} 0.2 \mathrm{M} \mathrm{Na}_{2} \mathrm{CO}_{3}$ solutions. Amount of the p-nitrophenol released from PNP-glycoside was quantified on a 96 microplate spectrophotometer (Bio-Rad, USA) at $405 \mathrm{~nm}$. The inhibitory rate of sample on $\alpha$-glucosidase was calculated by the following formula.

Inhibition $(\%)=\left[\mathrm{A}_{\text {blank }}-\left(\mathrm{A}_{\text {sample }}-\mathrm{A}_{\text {background }}\right)\right] / \mathrm{A}_{\text {blank }} \times 100$.

All the tests were run in triplicate. The $\mathrm{IC}_{50}$ values (concentration required to inhibit 50\% enzyme activity) were calculated by applying logarithmic regression analysis from the mean inhibitory values.

\section{Kinetics of inhibition against $\boldsymbol{\alpha}$-glucosidase}

Inhibition mode of the APL against $\alpha$-glucosidase activities was measured with the increasing concentration of p-nitrophenyl- $\alpha$-D-glucopyranoside as a substrate in the absence or presence of FC or TC at different concentrations. Inhibition type was determined by LineweaverBurk plot analysis of the data, which was calculated from the result according to Michaelis-Menten kinetics.

\section{1,1-Diphenyl-2-picrylhydrazyl radical scavenging activity}

Assay for the scavenging of stable free radical 1,1-diphenyl-2-picrylhydrazyl (DPPH) was carried out as reported earlier with some modifications [20]. Briefly, $100 \mu \mathrm{L}$ sample in methanol was mixed with $1.9 \mathrm{~mL}$ of $0.1 \mathrm{mM} \mathrm{DPPH}$ in ethanol. The concentration of the tested samples in the mixture was $0.25,0.5,2.5,5.0,25.0,50.0,100.0 \mu \mathrm{g} / \mathrm{mL}$, respectively. The reaction mixture was shaken well and incubated in dark at $37^{\circ} \mathrm{C}$ for $30 \mathrm{~min}$ and the absorbance was measured at $517 \mathrm{~nm}$. The blanks contained all the reaction reagents except the extract or positive control substances. BHT was used as positive control. The percentage scavenging values were calculated from the absorbance of the blank $\left(A_{0}\right)$ and of the sample $\left(A_{S}\right)$ using the following equation:

$$
\begin{aligned}
& \text { DPPH radicals scavenging activity }(\%) \\
& \quad=\left(1-\mathrm{A}_{\mathrm{S}} / \mathrm{A}_{0}\right) \times 100
\end{aligned}
$$

Where $A_{S}$ was the absorbance of the sample and $A_{0}$ was the absorbance of the blank (without sample).

\section{Hydroxyl radical scavenging activity}

The hydroxyl radical-scavenging assay was carried out using the method described by De Avellar and Jin with minor modifications [21]. $0.75 \mathrm{mM}$ 1,10-phenanthroline and $0.75 \mathrm{mM} \mathrm{FeSO}_{4}$ were prepared in $0.05 \mathrm{M}$ phosphate buffer ( $\mathrm{pH} 7.4$ ) and mixed thoroughly. $100 \mu \mathrm{L}$ of sample in methanol at different concentration of 5.0, 10.0, 50.0, 100.0, 500.0, 1000.0, $2000.0 \mu \mathrm{g} / \mathrm{mL}$ respectively, and $880 \mu \mathrm{L}$ of above solution (incubated at $37^{\circ} \mathrm{C}$ for $30 \mathrm{~min}$ ) was dispensed to test tubes and $20 \mu \mathrm{L}$ of $\mathrm{H}_{2} \mathrm{O}_{2}(0.01 \%)$ were added. The reaction mixture was incubated in dark at $37^{\circ} \mathrm{C}$ for $60 \mathrm{~min}$, and measured at $536 \mathrm{~nm}$. The hydroxyl radical scavenging activities were calculated using the following equation:

$$
\begin{aligned}
& \text { Hydroxyl radical scavenging activity }(\%) \\
& \quad=\left[\left(\mathrm{A}_{\mathrm{S}}-\mathrm{A}_{\mathrm{c}}\right) /\left(\mathrm{A}_{0}-\mathrm{A}_{\mathrm{c}}\right)\right] \times 100
\end{aligned}
$$

Where $A_{S}$, absorbance of the sample; $A_{C}$, absorbance of control solution containing 1,10-phenanthroline, $\mathrm{FeSO}_{4}$ and $\mathrm{H}_{2} \mathrm{O}_{2}$ without sample; $\mathrm{A}_{0}$, absorbance of blank solution containing 1,10-phenanthroline and $\mathrm{FeSO}_{4}$ without $\mathrm{H}_{2} \mathrm{O}_{2}$ and sample.

\section{ABTS radical scavenging assay}

ABTS radical-scavenging activity was measured by modifying the method described by Re et al. [22]. ABTS was dissolved in de-ionized water to $7 \mathrm{mM}$ concentration, and potassium persulphate was added to a concentration of $2.45 \mathrm{mM}$ (final concentration). After well mixed, the reaction mixture was left to stand at room temperature overnight (12-16 h) in the dark before usage (Fresh stocks of ABTS solution were prepared every five days due to 
self-degradation of the radical). $200 \mu \mathrm{L}$ sample in methanol at different concentrations of 1.25, 2.5, 12.5, 25.0, 125.0, 250.0, $500.0 \mu \mathrm{g} / \mathrm{mL}$ respectively was mixed with $0.3 \mathrm{~mL}$ $\mathrm{ABTS}^{\cdot+}$ solution and $0.5 \mathrm{~mL}$ distill water. The mixture was allowed to stand at room temperature for $2 \mathrm{~min}$, and the absorbance at $745 \mathrm{~nm}$ was immediately recorded. Ascorbic acid served as a positive control. All the tests were performed in triplicate and the graph was plotted with the mean values. The assay was first carried out on the percentage of inhibition which calculated by the following formula:

$$
\begin{aligned}
& \text { ABTS radical-scavenging activity (\%) } \\
& =\left(1-\mathrm{A}_{\mathrm{s}} / \mathrm{A}_{\mathrm{c}}\right) \times 100
\end{aligned}
$$

Where $A_{c}$ was the absorbance of the blank (without sample) and $A_{s}$ was the absorbance of the sample.

\section{Determination of the antilipid peroxidation activity with the $\beta$-carotene bleaching assay}

The anti-lipid peroxidation activity of the sample was evaluated using $\beta$-carotene-linoleic acid model system $[23,24] .1 \mathrm{~mL} \beta$-carotene $(0.2 \mathrm{mg} / \mathrm{mL})$ in chloroform was pipetted into a round-bottom flask $(50 \mathrm{ml})$ containing $25 \mu \mathrm{L}$ linoleic acid and $200 \mathrm{mg}$ Tween-40. After the mixture was evaporated to remove chloroform under vacuum, $100 \mathrm{~mL}$ of distilled water saturated with oxygen was added by vigorous shaking to form an emulsion. $2400 \mu \mathrm{L}$ of this emulsion was added into $100 \mu \mathrm{L}$ of the sample in methanol with different concentrations. As soon as the mixture was added to each tube, the zero time absorbance was measured at $470 \mathrm{~nm}\left(\mathrm{~A}_{\mathrm{S}}{ }^{0}\right)$. The emulsion system was incubated for $2 \mathrm{~h}$ at $50^{\circ} \mathrm{C}\left(\mathrm{A}_{\mathrm{S}}^{\mathrm{t}}\right)$. A blank without $\beta$-carotene was prepared for background subtraction $\left(\mathrm{A}_{\mathrm{c}}\right)$. BHT was used as a positive control. The test was carried out in triplicate. Results were calculated using the following equation:

$$
\begin{aligned}
& \text { Inhibiting activity of } \beta \text {-carotene bleaching (\%) } \\
& \quad=\left[1-\left(\mathrm{A}_{\mathrm{S}}{ }^{0}-\mathrm{A}_{\mathrm{S}}{ }^{\mathrm{t}}\right) /\left(\mathrm{A}_{\mathrm{c}}{ }^{0}-\mathrm{A}_{\mathrm{c}}{ }^{\mathrm{t}}\right)\right] \times 100
\end{aligned}
$$

\section{Statistical analysis}

All tests were performed in triplicate. Results were expressed as the means \pm SD $(n=3)$. The IC50 values were calculated from linear regression analysis. A paired-samples $\mathrm{T}$ test was used for the difference analysis between groups by using SPSS 19.0 software. Difference with a value of $p<0.01$ were considered statistically significant.

\section{Results and discussion}

Despite a great of efforts have been made in treatment of T2DM in clinic, poor effect accounted for a single target is still a major challenge. More and more researches suggested that the multi-target therapy combining with the control of postprandial hyperglycaemia and oxidative stress may become a promising therapy strategy because oxidative stress is mainly induced by postprandial hyperglycaemia [4]. There is increasing interest in screening of bioactive compounds from herbal plant with the ability to delay or prevent glucose absorption, and to reduce oxidative damage. APL, as Chinese traditional medicine, has been used to treat T2DM clinically for several decades, but its pharmaco-mechanism is not so clear. To address the mechanism at least to some degree, both $\alpha$-glucosidase inhibiting activity and antioxidant activity of the FC and the TC from APL were studied. Many traditionally medicinal plants and natural products have been tested for their inhibition of $\alpha$-glucosidase activities and anti-diabetic potential [10], but few researches about APL have been reported.

Based on the theory of the active components alignment, the FC and the TC were isolated from APL. The total flavonoids content in $\mathrm{FC}$ is $316.53 \pm 6.37 \mathrm{mg} / \mathrm{g}$ by using the aluminum chloride colorimetric method with quercetrin as a standard $\left(y=0.01718 c-0.00556, R^{2}=0.9994 ; x\right.$ was the concentration of the extract while $y$ was the absorbance of the flavonoids). By HPLC analysis, 10 flavonoids were identified and quantified: vitexin, rutin, hyperoside, luteolin-7O- $\beta$-D-glucopyranoside, quercitrin, quercetin, tiliroside, luteolin, apigenin and kaempferol (Table 1). Chromatographic profiles of flavonoids composition of FC are shown in Figure 2. We found that quercitrin, tiliroside and vitexin are abundant flavonoids which make up $64.3 \%$ of the 10 flavonoids.

The total triterpenoids content in TC is $415.97 \pm$ $5.15 \mathrm{mg} / \mathrm{g}$ with ursolic as a standard $(y=0.05584 x-$ 0.06093, $R^{2}=0.99949 ; x$ was the concentration of extract while $y$ was the absorbance of triterpenoids). And 6 triterpenoids were identified and quantified by using HPLC analysis: $1 \beta, 2 \beta, 3 \beta, 19 \alpha$-tetrahydroxy-12-en-28-oic acid,

Table 1 The contents of flavonoids in flavonoid compound (FC)

\begin{tabular}{ll}
\hline Compounds & Contents $\mathbf{( m g / g )}$ \\
\hline Vitexin & $24.2 \pm 1.2$ \\
Rutin & $10.8 \pm 0.4$ \\
Hyperoside & $9.8 \pm 0.5$ \\
Luteolin-7-O-ß-D-glucopyranoside & $8.4 \pm 0.8$ \\
Quercitrin & $73.6 \pm 2.6$ \\
Quercetin & $13.9 \pm 0.8$ \\
Tiliroside & $31.2 \pm 0.9$ \\
Luteolin & $14.7 \pm 1.1$ \\
Apigenin & $11.3 \pm 0.4$ \\
Kaempferol & $2.7 \pm 0.5$ \\
\hline
\end{tabular}

Note: Each value represents the mean \pm S.D. $(n=3)$. 


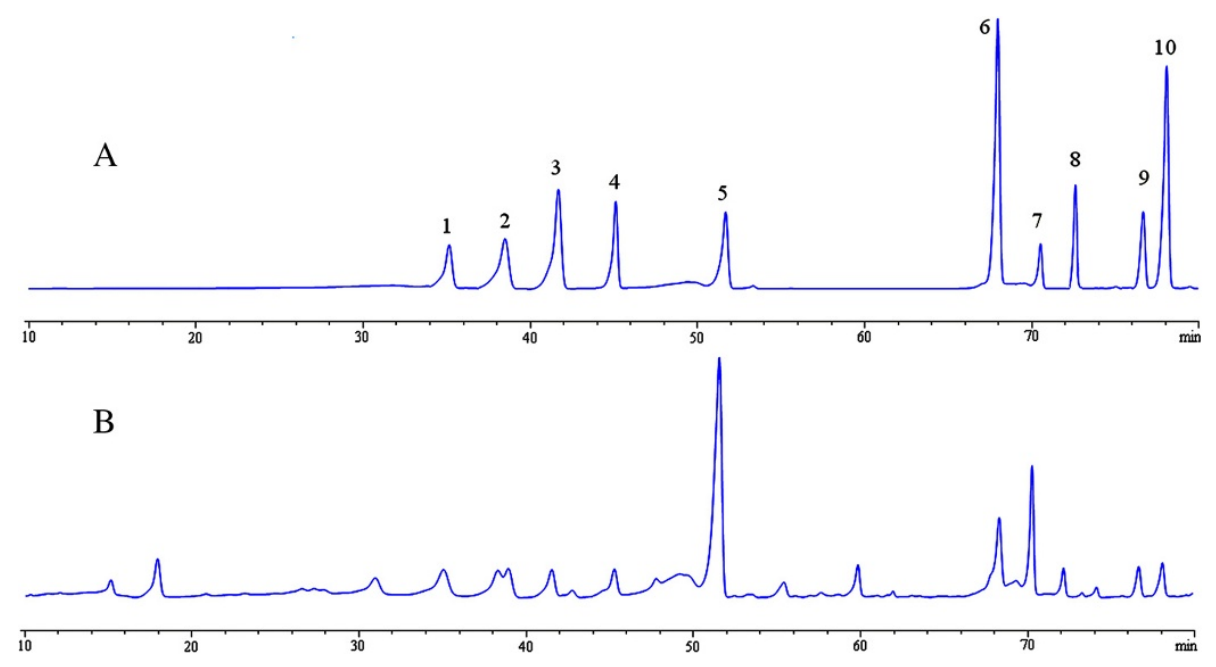

Figure 2 HPLC chromatogram of flavonoid compositions in flavonoid compound (FC). (A) standard flavonoids; (B) FC. Peaks: 1: vitexin; 2: rutin; 3: hyperoside; 4: luteolin-7-O-ß-D-glucopyranoside; 5: quercitrin; 6: quercetin; 7: tiliroside; 8: luteolin; 9: apigenin; 10: kaempferol.

tormentic acid, maslinatic acid, corosolic acid, oleanolic acid and ursolic acid (Table 2). Chromatographic profiles of triterpenoids composition of TC are shown in Figure 3. $1 \beta, 2 \beta, 3 \beta, 19 \alpha$-tetrahydroxy-12-en-28-oic acid is the most predominant triterpenoid in TC, contributing $265.2 \mathrm{mg} / \mathrm{g}$. The followings are corosolic acid $(100.9 \mathrm{mg} / \mathrm{g})$, maslinatic acid $(53.7 \mathrm{mg} / \mathrm{g})$, ursolic acid $(28.2 \mathrm{mg} / \mathrm{g})$, tormentic acid $(22.2 \mathrm{mg} / \mathrm{g})$, oleanolic acid $(6.7 \mathrm{mg} / \mathrm{g})$. The contents of these six triterpenoids in TC add up to $476.9 \mathrm{mg} / \mathrm{g}$.

\section{a-glucosidase inhibition activity}

Most importantly therapeutic approaches for decreasing PPHG were to prevent absorption of glucose by inhibition of $\alpha$-glucosidase. So the inhibitory effects of the FC and the TC from APL against $\alpha$-glucosidase were studied (Figure 4). And the $\mathrm{IC}_{50}$ (50\% inhibitory concentration) values were analyzed by SPSS software. Both the FC and the TC could inhibit the activity of $\alpha$-glucosidase in a dose-dependent manner at the concentrations of 1.67$41.67 \mu \mathrm{g} / \mathrm{mL}$. The maximum inhibition is found to be $94.5 \%$ and $87.5 \%$ at the $41.67 \mu \mathrm{g} / \mathrm{mL}$ of the FC and the TC, respectively. Compared with the $\mathrm{FC}\left(\mathrm{IC}_{50}=8.72 \mu \mathrm{g} / \mathrm{mL}\right)$,

Table 2 The contents of triterpenoids in triterpenoid compounds (TC)

\begin{tabular}{ll}
\hline Compounds & Contents $\mathbf{( m g / g )}$ \\
\hline Oleanolic acid & $6.7 \pm 0.4$ \\
Ursolic acid & $28.2 \pm 0.4$ \\
Maslinatic acid & $53.7 \pm 0.5$ \\
Corosolic acid & $100.9 \pm 7.5$ \\
Tormentic acid & $22.2 \pm 1.7$ \\
$1 \beta, 2 \beta, 3 \beta, 19$ a-tetrahydroxy-12-en-28-oic acid & $265.2 \pm 2.0$ \\
\hline
\end{tabular}

Note: Each value represents the mean \pm S.D. $(n=3)$. the TC exhibits the stronger efficiency with the $\mathrm{IC}_{50}$ of $3.67 \mu \mathrm{g} / \mathrm{mL}$. The activities of three complexes with mass ratio of $\mathrm{FC}$ and $\mathrm{TC}$ as 4:1, 1:1 and 1:4 were also determined. The data in Figure 5 show that the complex with the mass ratio of FC and TC as 4:1 exhibits the best inhibition activity against $\alpha$-glucosidase among these three complexes. The $\mathrm{IC}_{50}$ values of three complexes with mass ratio of FC and TC as 4:1, 1:1 and 1:4 are 3.92, 10.39 and $9.39 \mu \mathrm{g} / \mathrm{mL}$, respectively. Furthermore, the studies of enzyme kinetics (see Figure 6) demonstrated that the FC exhibits competitive inhibition against $\alpha$-glucosidase, while TC exhibits noncompetitive inhibition.

Previously some plant extracts have been reported to inhibit $\alpha$-glucosidase activity, such as the ethanol exract of Andrographis paniculata $\left(\mathrm{IC}_{50}=17.20 \mathrm{mg} / \mathrm{mL}\right)$ [25], the ethanol extracts of Mangifera indica bark $\left(\mathrm{IC}_{50}=\right.$ $314 \mu \mathrm{g} / \mathrm{mL}$ ) [26], and the butanol extract of Acosmium panamense $\left(\mathrm{IC}_{50}=109 \mu \mathrm{g} / \mathrm{mL}\right)$ [27]. Compared with these reported natural extracts, the FC and the TC from APL showed excellent $\alpha$-glucosidase inhibitory activities. In addition, some natural products could exhibit different inhibition modes against $\alpha$-glucosidase, such as the methanol fraction of Bitter melon in an uncompetitive manner with an $\mathrm{IC}_{50}$ value of $2.60 \mathrm{mg} / \mathrm{mL}$ [28]. Our results also show that the FC and the TC from APL inhibit $\alpha$-glucosidase in different modes, i.e. the $\mathrm{FC}$ in competitive mode and the TC in noncompetitive inhibition mode. In addition, it was reported that corosolic acid from Lagerstroemia apeciosa leaves exhibit a nocompetitive mode with an $\mathrm{IC}_{50}$ value of $3.53 \mu \mathrm{g} / \mathrm{mL}$ [29]. And corosolic acid with the content of $100.9 \mathrm{mg} / \mathrm{g}$ also is the second abundant triterpenoid in the TC (Table 2). Furthermore, the inhibition activities against $\alpha$-glucosidase of the complexes with different mass ratio 




Figure 3 HPLC chromatogram of triterpenoid compositions in triterpenoid compound (TC). (A) standard triterpenoids; (B) TC. Peaks: 1: $1 \beta$,

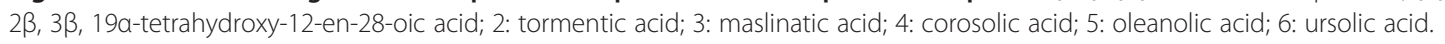

of FC and TC were assayed based on their different inhibitory modes. The result reveals that the combination with mass ratio of FC and TC as 4:1 has superiority inhibition activity against $\alpha$-glucosidase to the other complexes with mass ratio of FC and TC as 1:4 and 1:1 at the concentration range of $4.17-33.33 \mu \mathrm{g} / \mathrm{mL}$. But when the concentration is greater than $33.33 \mu \mathrm{g} / \mathrm{mL}$, the complexes (FC: $\mathrm{TC}=1: 4, \mathrm{~g} / \mathrm{g}$ ) has better $\alpha$-glucosidase inhibition activity than others. Based on the results mentioned above, we could propose that, at the low concentration, the competitive inhibition is dominant, but the noncompetitive inhibition has a little advantage at the high concentration. So we think that the APL has a potential treating effect on T2MD, which is attributed partly to the

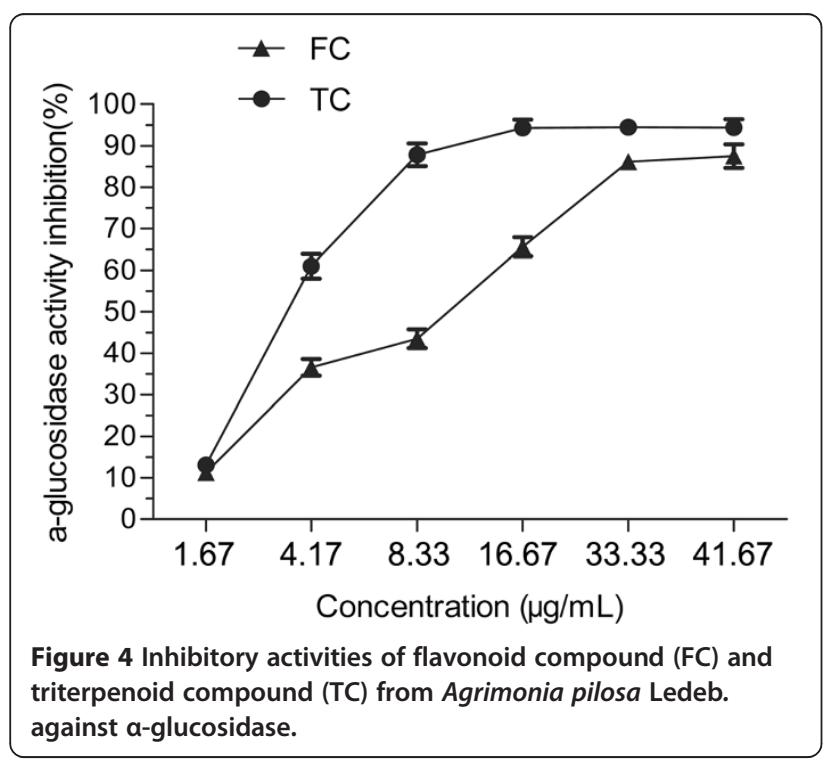

$\alpha$-glucosidase inhibition activities of the FC and the TC for the control of the postprandial hyperglycaemia.

\section{In vitro antioxidant activity}

In order to obtain the credible conclusion, four assays including DPPH scavenging assay, hydroxyl radical scavenging assay, ABTS radical scavenging assay and $\beta$-carotene-linoleic acid assay were employed to evaluate antioxidant activities of the FC and the TC.

The free radical scavenging activities of the $\mathrm{FC}$ and the TC were evaluated using DPPH scavenging assay, hydroxyl radical scavenging assay and ABTS radical scavenging assay. As shown in Figures 7, 8 and 9, the FC has significant radical scavenging activity in a dose-

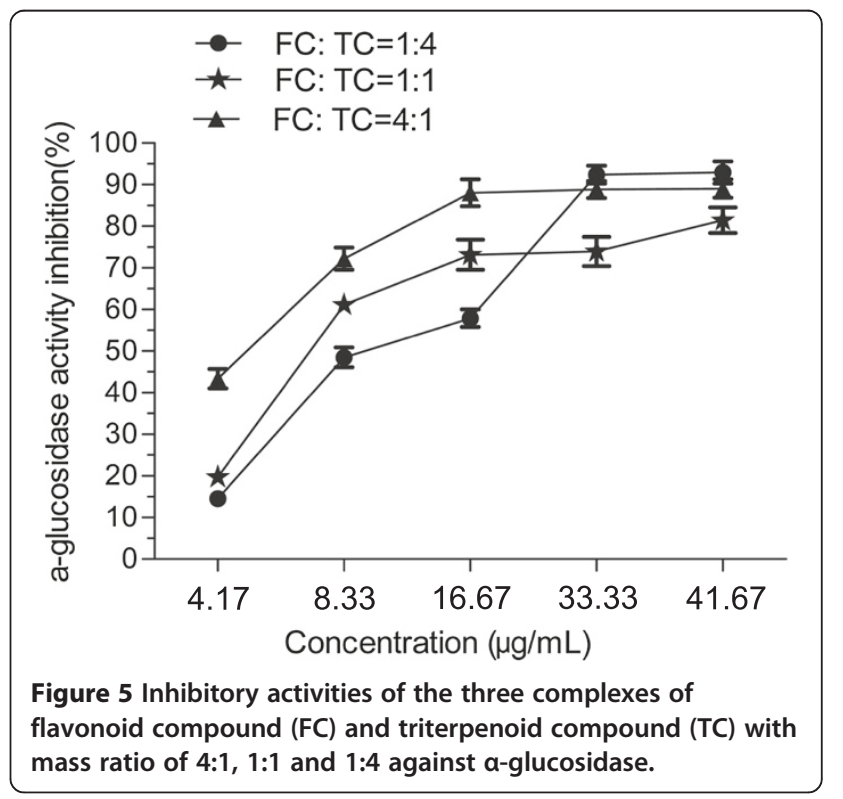




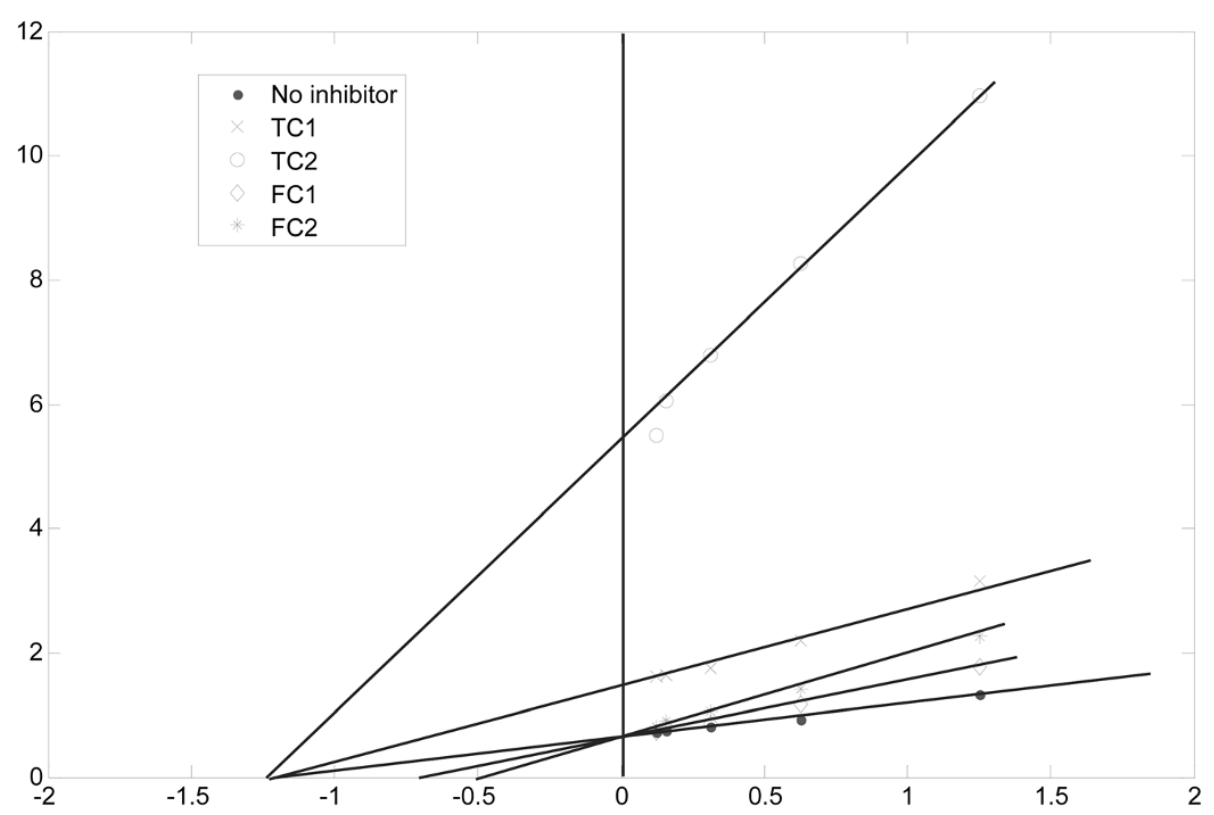

Figure 6 Lineweaver-Burk plot for the inhibition mode of flavonoid compound (FC) and triterpenoid compound (TC) against a-glucosidase. No inhibitor: absence of sample as a control; TC1: 8ug/mL; TC2: 16ug/mL; FC1: 8ug $/ \mathrm{mL} ; \mathrm{FC2}: 16 \mathrm{ug} / \mathrm{mL}$.

dependent manner, which is comparable with BHT. The $\mathrm{EC}_{50}$ values of the $\mathrm{FC}$ on $\mathrm{DPPH}$ radical, hydroxyl radical and ABTS radical are $7.7 \mu \mathrm{g} / \mathrm{mL}, 3.6 \mu \mathrm{g} / \mathrm{mL}$ and $5.9 \mu \mathrm{g} / \mathrm{mL}$, respectively (Table 3 ). The $\mathrm{EC}_{50}$ values of BHT which was used as positive control on DPPH radical and hydroxyl radical are $7.7 \mu \mathrm{g} / \mathrm{mL}$ and $3.1 \mu \mathrm{g} / \mathrm{mL}$, respectively. And the $\mathrm{EC}_{50}$ values of the ascorbic acid used as positive control on ABTS is $2.5 \mu \mathrm{g} / \mathrm{mL}$. Compared with the $\mathrm{FC}$, the $\mathrm{TC}$ has weaker radical scavenging activity with $\mathrm{EC}_{50}$ values on DPPH radical, hydroxyl radical and ABTS radical of $>100.0 \mu \mathrm{g} / \mathrm{mL}, 35.2 \mu \mathrm{g} / \mathrm{mL}$ and $>100.0 \mu \mathrm{g} / \mathrm{mL}$, respectively (Table 3 ).

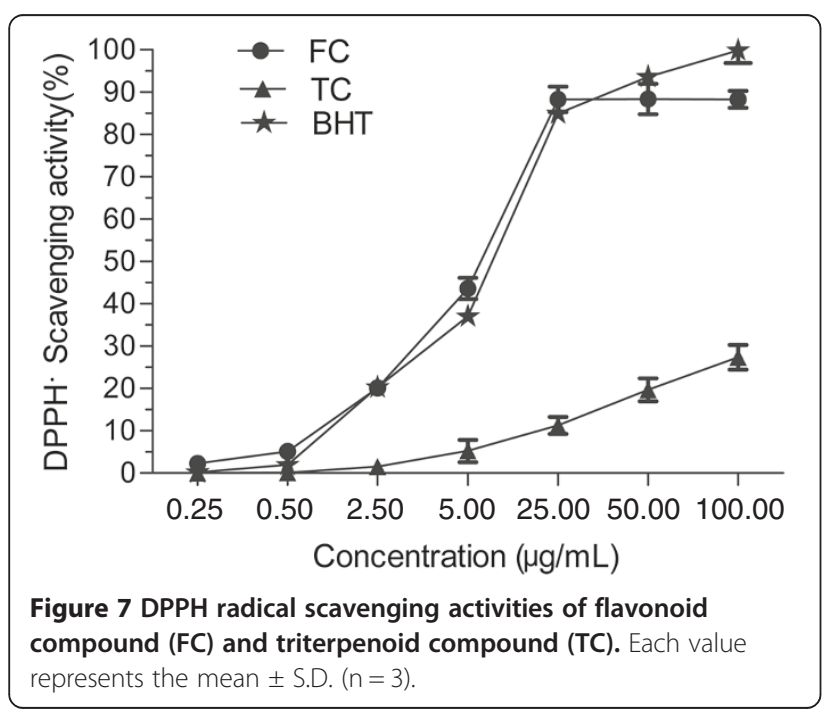

The anti-lipid peroxidation activity of the FC and the TC were determined by using the $\beta$-carotene-linoleic acid system and the results were shown in Figure 10. All of the tested samples have inhibition activity on lipid peroxidation in a dose-dependent manner $(0.2 \mu \mathrm{g} / \mathrm{mL}-80.0 \mu \mathrm{g} / \mathrm{mL})$. BHT shows an excellent inhibitory activity $\left(\mathrm{IC}_{50}=1.8 \mu \mathrm{g} / \mathrm{mL}\right)$, while the $\mathrm{IC}_{50}$ values of the FC and the TC are $41.8 \mu \mathrm{g} / \mathrm{mL}$ and $98.5 \mu \mathrm{g} / \mathrm{mL}$, respectively. It is demonstrated that FC has moderate anti-lipid peroxidation activity.

Among the quantified 10 flavonoids in FC, 6 flavonoids including quercetin, luteolin, rutin, hyperoside, luteolin-7-O- $\beta$-D-glucopyranoside and quercitrin have

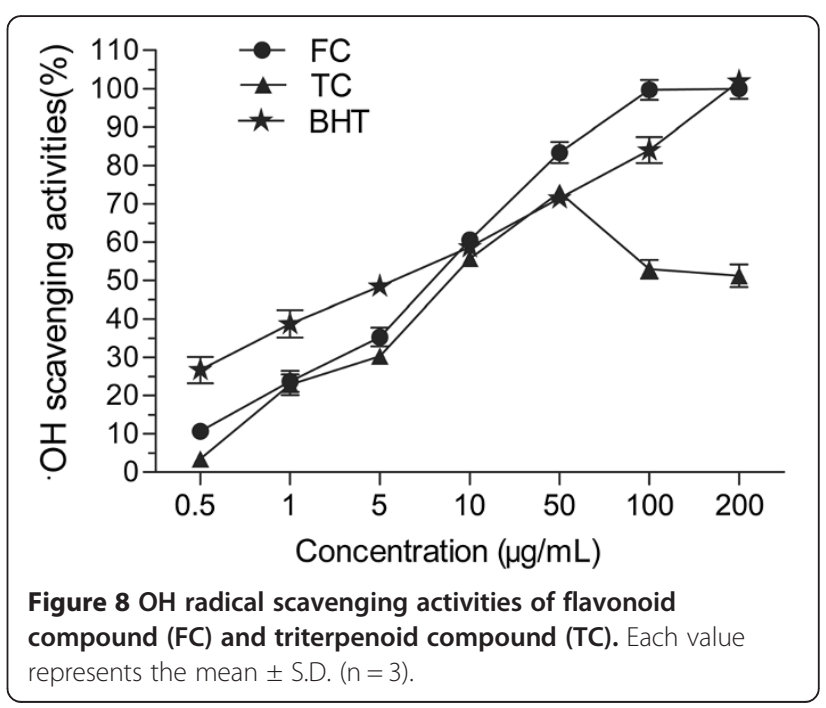




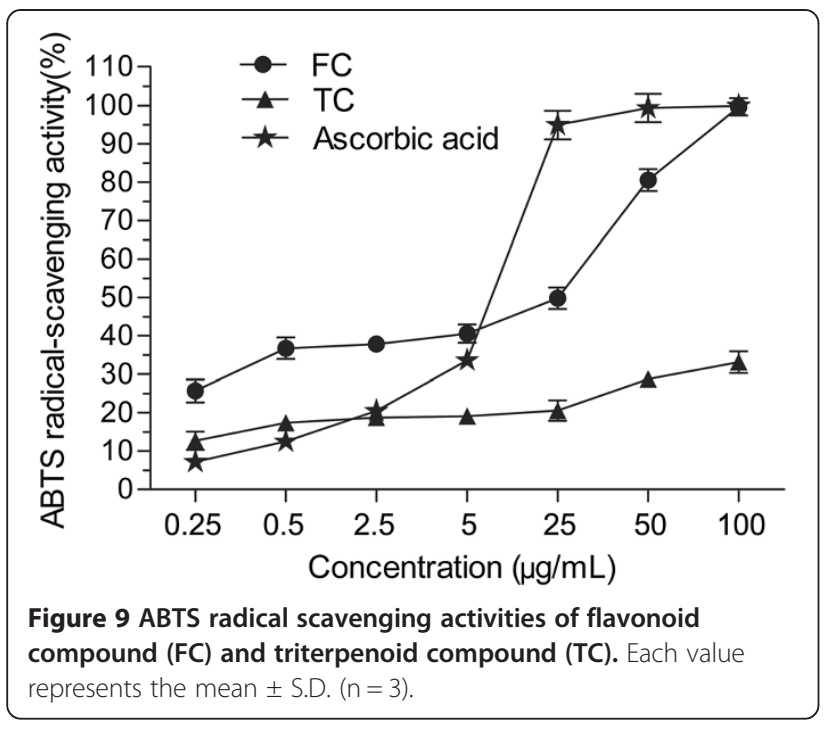

excellent scavenging activities on radical due to the o-catechol group $\left(3^{\prime}, 4^{\prime}-\mathrm{OH}\right)$ in $\mathrm{B}$ ring [30]. These 6 flavonoids making up $65.4 \%$ of the quantified 10 flavonoids could be responsible for the FC's significant scavenging activities on DPPH radical, hydroxyl radical and ABTS radical. Radicals induced by postprandial hyperglycaemia or other reasons $[4,31]$, such as superoxide anion radical and hydroxyl radical, have the very high reactivity which enables them to react with a wide range of molecules, such as protein, lipids, and nucleotides leading to occurrence and development of a variety of diseases including T2DM [3,32]. The remarkable scavenging activities of the FC on radical imply that the FC could be responsible for the good clinical effects of APL on T2MD targeting oxidative stress.

\section{Conclusions}

In conclusion, our findings suggest that the $\mathrm{FC}$ and the $\mathrm{TC}$ could be responsible for the good clinical effects of

Table 3 The $\mathrm{EC}_{50}$ values and $\mathrm{IC}_{50}$ values of flavonoid compound (FC) and triterpenoid compounds (TC) from agrimonia pilosa ledeb

\begin{tabular}{|c|c|c|c|c|}
\hline \multirow[t]{2}{*}{ Compounds } & \multicolumn{3}{|c|}{ Radical scavenging $\left(\mathrm{EC}_{50}, \mu \mathrm{g} / \mathrm{mL}\right)$} & \multirow{2}{*}{$\begin{array}{l}\beta \text {-carotene } \\
\text { bleaching } \\
\left(\mathrm{IC}_{50}, \mu \mathrm{g} / \mathrm{mL}\right)\end{array}$} \\
\hline & DPPH. &. $\mathrm{OH}$ & ABTS & \\
\hline$\overline{F C}$ & $7.7 \pm 0.4$ & $3.6 \pm 0.2$ & $5.9 \pm 0.4^{*}$ & $41.8 \pm 1.0^{*}$ \\
\hline $\mathrm{TC}$ & $>100.0$ & $35.2 \pm 0.3^{*}$ & $>100.0$ & $98.5 \pm 1.2^{*}$ \\
\hline BHT & $7.7 \pm 0.2$ & $3.1 \pm 0.1$ & - & $1.8 \pm 0.2$ \\
\hline Ascorbicacid & - & - & $2.5 \pm 0.1$ & - \\
\hline
\end{tabular}

Note: An asterisk (*) indicates a significant difference at the $p<0.01$ level vs positive control.

Each value represents the mean \pm S.D. $(n=3)$.

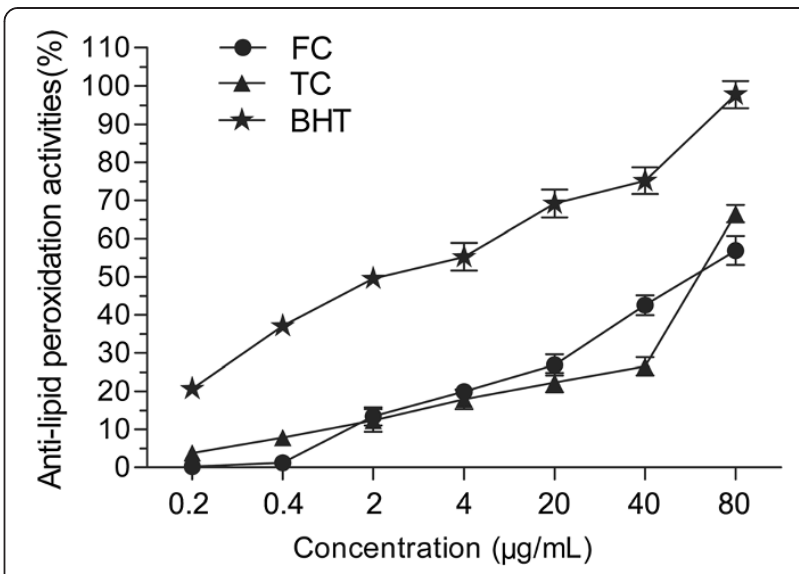

Figure 10 Anti-lipid peroxidation activities in the $\beta$-Carotenelinoleic acid system of flavonoid compound (FC) and triterpenoid compound (TC) from Agrimonia pilosa Ledeb. Each value represents the mean \pm S.D. $(n=3)$.

APL on T2MD through targeting oxidative stress and postprandial hyperglycaemia. So APL may be good sources of natural antioxidants and $\alpha$-glucosidase inhibitors exhibiting remarkable potential application in the therapy of T2DM. Further investigations should be taken to illustrate the pharmaco-mechanism deeply and to isolate the active components.

\section{Competing interests}

The authors declare that they have no competing interests.

\section{Authors' contributions}

$\mathrm{XL}$ carried out the experimentation, acquisition and analysis of data and drafting of the manuscript. LZ conceived, designed, supervised the study and revised the manuscript. JT provided technical support and advice in the experiments and revised the manuscript. XZ carried out the acquisition of the Agrimonia pilosa Ledeb extracts. LX \& XY carried out the HPLC analysis of FC and TC. BW supervised the study and helped in drafting and revision of manuscript. All authors have read and approved the final manuscript.

\section{Acknowledgments}

This work was supported by the Fundamental Research Funds for the Central Universities (Project No. CQDXWL-2012-130), Program for Innovation Team Building at Institutions of Higher Education in Chongqing (KJTD201325), the Natural Science Foundation Project of CQ CSTC (No. 2011BB5109), and Visiting Scholar Foundation of Key Laboratory of Biorheological Science and Technology (Chongqing University), Ministry of Education (CQKLBST-2012-007)

\section{Author details}

'Key Laboratory of Biorheological Science and Technology (Chongqing University), Ministry of Education, College of Bioengineering, Chongqing University, No. 174, Shapingba Main Street, Chongqing 400030, China. ${ }^{2}$ School of Biological \& Chemical engineering, Chongqing University of Education, Chongqing 400067, China. ${ }^{3}$ College of Life Sciences, Chongqing Normal University, Chongqing 401331, China.

Received: 2 August 2013 Accepted: 6 January 2014

Published: 10 January 2014 


\section{References}

1. Stumvoll M, Goldstein BJ, Haeften TW: Type 2 diabetes: principles of pathogenesis and therapy. Lancet 2005, 365:1333-1346.

2. Labonte ED, Kirby RJ, Schildmeyer NM, Cannon AM, Huggins KW, Hui DY: Group 1B phospholipase A(2)-mediated lysophospholipid absorption directly contributes to postprandial hyperglycemia. Diabetes 2006 55:935-941.

3. Maritim AC, Sanders RA, Watkins JB: Diabetes, oxidative stress, and antioxidants: a review. J Biochem Mol Toxic 2003, 17:24-38.

4. Wright E, Scism-Bacon JL, Glass LC: Oxidative stress in type 2 diabetes: the role of fasting and postprandial glycaemia. Int J Clinic Pract 2006, 60:308-314

5. Mooradian AD, Thurman JE: Drug therapy of postprandial hyperglycaemia. Drugs 1999, 57:19-29.

6. Bischoff H: Pharmacology of alpha-glucosidase inhibition. Eur I Clin Invest 1994, 24:3-10.

7. Johnston PS, Lebovitz HE, Coniff RE, Simonson DC, Raskin P, Munera CL: Advantages of a-Glucosidase Inhibition as monotherapy in elderly type 2 diabetic patients. J Clin Endocrin Metab 1998, 83:1515-1522.

8. Hanefeld M: The role of acarbose in the treatment of non-insulindependent diabetes mellitus. J Diabetes Complicat 1998, 12:228-237.

9. Chakrabarti R, Rajagopalan R: Diabetes and insulin resistance associated disorders: disease and the therapy. Curr Sci 2002, 83:1533-1538.

10. Benalla W, Bellahcen S, Bnouham M: Antidiabetic medicinal plants as a source of alpha glucosidase inhibitors. Curr Diabetes Rev 2010, 6:247-254

11. Rahimi R, Nikfar S, Larijani B, Abdollahi M: Review on the role of antioxidants in the management of diabetes and its complications. Biomed Pharmcother 2005, 59:365-373.

12. Johansen JS, Harris AK, Rychly DJ, Ergul A: Oxidative stress and the use of antioxidants in diabetes: linking basic science to clinical practice. Cardiovasc Diabetol 2005, 4:5-15.

13. Pharmacopoeia Commission of People's Republic of China: Chinese Pharmacopoeia, Part I. Beijing: Chemical Industry Pres; 2005:67.

14. Kato H, Li W, Koike M, Wang YH, Koike K: Phenolic glycosides from Agrimonia pilosa. Phytochemistry 2010, 71:1925-1929.

15. Kouno I, Baba N, Ohni Y, Kawano N: Triterpenoids from Agrimonia pilosa. Phytochemistry 1998, 27:297-299.

16. Tundis R, Loizzo MR, Menichini F: Natural products as alpha-Amylase and alpha-glucosidase inhibitors and their hypoglycaemic potential in the treatment of diabetes: an update. Mini-Rev Med Chem 2010, 10:315-331.

17. Cazarolli LH, Zanatta L, Alberton EH, Figueiredo MSRB, Folador P, Damazio RG, Pizzolatti MG, Silva FRMB: Flavonoids: prospective drug candidates. Mini-Rev Med Chem 2008, 8:1429-1440.

18. Pharmacopoeia Commission of People's Republic of China: Chinese Pharmacopoeia, Part I. Beijing: Chemical Industry Pres; 2005:239.

19. Kang WY, Song YL, Zhang L: Alpha-Glucosidase inhibitory and antioxidant properties and antidiabetic activity of Hypericum ascyron L. Med Chem Res 2011, 20:809-816.

20. Blois MS: Antioxidant determinations by the use of a stable free radical. Nature 1958, 181:1199-1200.

21. De Avelar IGJ, Magalhaes MMM, Silva AB, Souza LL, Leitao AC, Hermes-Lima M: Reevaluating the role of 1,10-phenanthroline in oxidative reactions involving ferrous ions and DNA damage. BBA-Gen Subjects 2004, 1675:46-53.

22. Re R, Pellegrini N, Proteggente A, Pannala A, Yang M, Rice-Evans C: Antioxidant activity applying an improved ABTS radical cation decolorization assay. Free Radical Bio Med 1999, 26:1231-1237.

23. Kabouche A, Kabouche Z, Ozturk M, Kolak U, Topcu G: Antioxidant abietane diterpenoids from Salvia barrelieri. Food Chem 2007, 102:1281-1287.

24. Miller HE: A simplified method for the evaluation of antioxidants. J Am Oil Chem Soc 1971, 48:91.

25. Subramanian $R$, Asmawi MZ, Sadikun A: In vitro alpha-glucosidase and alpha-amylase enzyme inhibitory effects of Andrographis paniculata extract and andrographolide. Acta Biochim Pol 2008, 55:391-398.

26. Prashanth D, Amit A, Samiulla DS, Asha MK, Padmaja R: a-Glucosidase inhibitory activity of Mangifera indica bark. Fitoterapia 2001, 72:686-688.

27. Andrade-Cetto A, Becerra-Jimenez J, Cardenas-Vazquez R: a-glucosidase inhibiting activity of some Mexican plants used in the treatment of type 2 diabetes. J Ethnopharmacol 2008, 116:27-32.
28. Uebanso T, Arai H, Taketani Y, Fukaya M, Yamamoto H, Mizuno A, Uryu K, Hada T, Takeda E: Extracts of Momordica charantia suppress postprandial hyperglycemia in rats. J Nutr Sci Vitaminol 2007, 53:482-488.

29. Hou WL, Li YF, Zhang Q, Wei X, Peng AH, Chen LJ, Wei YQ: Triterpene acids isolated from Lagerstroemia speciosa leaves as alpha-glucosidase inhibitors. Phytother Res 2009, 23:614-618.

30. Mendes APS, Borges RS, Neto AMJC, De Macedo LGM, Da Silva ABF: The basic antioxidant structure for flavonoid derivatives. J Mol Model 2012, 18(9):4073-4080

31. Moskovitz J, Yim MB, Chock PB: Free radicals and disease Arch. Biochem Biophys 2002, 397:354-359.

32. Halliwell B: Antioxidants and human disease: a general introduction. Nutr Rev 1997, 55:S44-S52.

\section{doi:10.1186/1472-6882-14-12}

Cite this article as: Liu et al: Glucosidase inhibitory activity and antioxidant activity of flavonoid compound and triterpenoid compound from Agrimonia Pilosa Ledeb. BMC Complementary and Alternative Medicine 2014 14:12.

\section{Submit your next manuscript to BioMed Central and take full advantage of:}

- Convenient online submission

- Thorough peer review

- No space constraints or color figure charges

- Immediate publication on acceptance

- Inclusion in PubMed, CAS, Scopus and Google Scholar

- Research which is freely available for redistribution 